\title{
"É PRECISO SER BEM VISTO, NÃO MANCHAR A REPUTAÇÃO, SE DAR O RESPEITO": DOS REGIMES DE VISIBILIDADE NAS TRAJETÓRIAS DE HOMENS HOMOSSEXUAIS*
}

\author{
"YOU HAVE TO BE WELL REGARDED, NOT SMEAR THE REPUTATION, \\ GIVE RESPECT": REGIMES OF VISIBILITY IN \\ THE PATHS OF HOMOSEXUAL MEN
}

\begin{abstract}
Resumo
Neste artigo recupero a trajetória de três homens homossexuais com vistas a problematizar o manejo em torno do processo de "saída do armário" e da publicização, ou não, das orientações sexuais e identidades de gênero destes homens, processo entendido como uma instância micropolítica que possui íntima relação com o aspecto emocional, contudo extrapola suas zonas de conforto diante de situações que são vivenciadas socialmente e que grafam no corpo a maneira como os sujeitos devem se comportar. Para tanto, procuro compreender o acionamento das noções êmicas de "respeito" e "pinta" e articulá-las a processos de constituição de regimes de visibilidades. Ao percorrer determinadas trajetórias, verifiquei que: maneiras diferenciadas de ver e de lidar com a afirmação de uma identidade homossexual, por exemplo na família de origem e nos espaços públicos, compõem o arsenal de possibilidades e de posturas corporais dos entrevistados, nos fazendo refletir sobre os agenciamentos de padrões identitários individuais e suas relações a respeito do modo como tais padrões são imaginados.
\end{abstract}

Palavras-chave: Homens homossexuais. Regimes de visibilidade. Discrição. "Respeito". "Pinta”.

\begin{abstract}
In this article, I retrieve the paths of three homosexual men to question the management around the process of "coming out" and of publicity, or not, about sexual orientations and gender identities of these men. A process understood as a micro instance that has a close relationship with the emotional aspect, but goes beyond their comfort zones in situations that are experienced socially and which mark in the body how the subject should behave. Therefore, I try to understand the activation of the emic notions of "respect" and "camp it up" and link them to broader questions about regimes of visibility. Go to certain paths, I found that: different ways of seeing and dealing with the affirmation of a homosexual identity, for example in the family of origin and in public areas, make up the arsenal of possibilities and body postures of respondents, making us reflect on assemblages of individual selfhood and their relationships about how such standards are imagined.
\end{abstract}

Keywords: Homosexual men. Regimes of visibility. Discretion. "Respect”. "Camp it up".

\footnotetext{
* Esta é uma versão atualizada do paper que apresentei como trabalho final na disciplina Antropologia das Emoções (ofertada pelo Departamento de Antropologia da Universidade de São Paulo, no segundo semestre de 2012), ministrada pela Profa. Dra. Laura Moutinho, a quem agradeço pelas elucidativas contribuições. Em um segundo momento, utilizei a versão antiga do texto, enquanto comunicação oral no III Seminário Enlaçando Sexualidades, realizado no período de 15 a 17 de maio de 2013, em Salvador (BA). Vale lembrar que todas as palavras ou frases grafadas em itálico entre aspas se referem às falas dos entrevistados (e, em alguns casos, comentários meus sobre conversas em campo, com amigos e terceiros) e seus nomes foram desidentificados.
}

\footnotetext{
Ramon Reis

Doutor em Antropologia Social pela Universidade de São Paulo. Atualmente sou professor contratado pela Secretaria de Estado de Educação do Pará.

E-mail: ramonrei@gmail.com
} 


\section{Introdução}

A feitura deste artigo se insere em dois momentos de minha trajetória acadêmica, quais sejam: I - recuperação de algumas questões do terceiro capítulo da pesquisa que realizei no mestrado (Reis, 2012a) ${ }^{1}$; II - composição de trabalho final para a disciplina Antropologia das Emoções, ministrada pela Profa. Dra. Laura Moutinho, no âmbito do Programa de Pós-Graduação em Antropologia Social (PPGAS) da Universidade de São Paulo (USP). Para tanto, procuro articular questões de gênero (por meio da noção de performance de gênero ${ }^{2}$ ) ao processo de constituição de regimes de visibilidade na trajetória de três homens homossexuais, relacionando, sempre que possível, com alguns autores lidos durante o curso ${ }^{3}$.

De antemão, quero ressaltar que não se trata de um texto que dialoga diretamente com o campo da antropologia das emoções, situando-o apenas como associação analítica e não enquanto foco principal do exame das entrevistas. $\mathrm{O}$ argumento que percorro tem como base a articulação com pesquisas inseridas dentro do campo dos estudos de gênero e sexualidade; cito, por exemplo, meu recurso direto, em partes do texto, ao refinamento argumentativo proposto por Judith Butler (2013 e 2014) sobre performances e regulações de gênero,

1 A pesquisa que desenvolvi no mestrado lançou olhar para a constituição de relações entre homens homossexuais em dois espaços de sociabilidade homossexual da capital paraense, as boates Lux e Malícia. Foi financiada pela Coordenação de Aperfeiçoamento de Pessoal de Nível Superior (CAPES) e orientada pela Profa. Dra. Cristina Donza Cancela.

2 Cf. Butler (2013), para quem a performance de gênero é um ato performativo. A performance, enquanto uma ilusão imaginativa proposta pelas Drag Queens revela uma estrutura imitativa e contingente falsamente naturalizada por uma unidade ficcional regular e coerente; constantemente rematerializada pela voz, gesto e corpo (Cf. Oliveira, 2006).

3 Por exemplo: Das (2011), Epstein (1969), Fassin (2008), Fonseca (2000), Gluckman (1963), Lutz \& White (1986), Moutinho et al. (2010), Simões et al. (2010). Nesse amplo universo científico, que dá suporte, direta ou indiretamente, ao campo da antropologia das emoções, estão presentes as seguintes querelas: os interessados no aspecto transcultural das emoções trazem consigo um interesse etnológico e evolutivo, psicodinâmico e senso comum naturalista, constituindo uma linguagem universal; enquanto aqueles interessados pelo aspecto da construção social e cultural das emoções, evocam um variado número de tradições, incluindo a etnopsicologia, a estrutura social, a linguística e a desenvolvimentista. Desta feita, há que se compreender que existe uma distinção entre emoção, definida como sentimento privado que não costuma estar motivada pelo aspecto cultural ou articulada socialmente, e sentimentos definidos como símbolos articulados socialmente e expectativas comportamentais (Cf. Lutz \& White, 1986). além da recuperação pontual da clássica noção de papéis sexuais e de gênero presente em Peter Fry e Edward Macrae (1991).

Para a escrita da dissertação, especificamente do terceiro capítulo, a intenção foi cotejar o material de pesquisa a partir da exposição das trajetórias de nove homens homossexuais entrevistados: suas identificações enquanto "homossexuais", as relações estabelecidas com a família, amigos e terceiros. As falas e reflexões despontaram como um dos aspectos mais importantes do capítulo, fazendo com que o leitor refletisse sobre a constituição do sujeito e de suas construções identitárias e performáticas auto-imputáveis e imagináveis. Vale ressaltar que neste artigo, por conta da economia do texto, lanço mão de três dessas trajetórias, procurando fazer conexão entre questões recorrentes nas falas.

Nesse sentido, as narrativas que serão expostas se inserem numa discussão que procura questionar o campo do privado, propondo uma problematização do aspecto micro, entendido aqui como uma instância micropolítica que possui íntima relação com o fator emocional, contudo extrapola suas zonas de conforto diante de situações que são vivenciadas socialmente (por meio de redes de amizade que se formam) e que grafam no corpo (performance corporal) a maneira como os sujeitos devem se comportar.

Grafar no corpo, por meio da construção de arquétipos masculinos e femininos precários, uma compulsória forma/norma de ser e estar é o modo problemático com que cada interlocutor deste texto aventa e dá sentido aos seus percursos. Nesta chave, Butler (2013) nos dá suporte para pensarmos que a noção clássica de sujeito e de identidade se refere a um efeito e a uma matéria que se pretende coerente, contínua e inquestionável. No ataque crítico a tais "verdades", Butler questiona o estabelecimento de "linhas causais ou expressivas de ligação entre o sexo biológico, o gênero culturalmente constituído e a 'expressão' ou 'efeito' de ambos na manifestação do desejo sexual por meio da prática sexual" (idem: 38 ).

É justamente esse peso das expectativas de gênero (Adichie, 2014) que produzem o que Butler (2014) vai chamar de "parâmetros de pessoas", algo que procurarei perseguir. Este argumento ganha maior rentabilidade textual a partir de uma não circunscrição ao foro íntimo dos entrevistados, afinal não se trata de 
uma etnografia da intimidade, que gera uma oposição entre público versus privado, mas sim do quanto práticas, construções identitárias e performances são moralizadas cotidianamente dentro e fora de casas, quartos, banheiros etc ${ }^{4}$.

Ao mencionar o caráter micropolítico da emoção, quero mostrar que não se trata apenas de uma constituição individual, de um indivíduo que se realiza em si mesmo. Se no início a visualização dessa emoção era referendada como um sentimento do íntimo, do privado, a partir do jogo entre aceitação, discrição e publicização, é possível colocar em questão esse sentimento uno, trazer à tona esse universo particular. É preciso, antes de mais nada, compreendermos que tais regimes de visibilidade têm na materialidade do poder o exercício sobre o próprio corpo dos indivíduos (Foucault, 2007 [1979]). Para tanto, procuro compreender o acionamento das noções êmicas de "respeito" e "pinta" e articulá-las ao modo como cada interlocutor elabora seus regimes de visibilidade.

Nesse movimento de problematização do aspecto emocional, tangenciado pelas questões de gênero e por regimes de visibilidade específicos, dois pontos chamam a atenção: um deles diz respeito à noção de rede (Epstein, 1969) $)^{5}$. As redes de amizade formadas durante o processo de constituição do sujeito propiciam um alicerce de conduta e funcionam como mola propulsora para a afirmação da identidade "homossexual". Outro ponto a ser levado em consideração é o aspecto da encenação $0^{6}$ : agenciam-se desejabilidades, violências, performances, normas.

Portanto, ao percorrer determinadas trajetórias, verifiquei que: maneiras diferenciadas de ver e lidar com a constituição de subjetividades homossexuais compõem

4 Didier Fassin (2008), de maneira enfática e recorrente, nos mostra que as/os antropólogas/os devem se preocupar com a moral (muito mais com uma antropologia da moral que uma moral da antropologia) como campo de estudo, assim como fazem com a política, religião, medicina etc. De todo modo, não há como negar que tem aumentado o interesse por questões morais na sociedade, bem como na própria disciplina, a antropologia.

$5 \mathrm{Na}$ definição do conceito de rede proposto por Epstein (1969), devese levar em conta uma série de variáveis: os papéis-componentes que entram na rede, o grau de "malha" ou coerência entre esses papéis e o peso relativo ou intensidade de cada relação; lembrando que mesmo nas relações construídas a partir de um papel-componente semelhante isso não significa que eles são de "qualidade" igual.

6 Sobre estudos que mostram como a encenação (leia-se agência) é aspecto constituinte das relações sociais, ver: Das (2011), McClintock (2003), Mahmood (2006). o arsenal de possibilidades e de posturas corporais dos entrevistados, fazendo-nos refletir sobre os agenciamentos através da composição de padrões identitários individuais e suas relações a respeito do modo como tais padrões são imaginados.

A seguir exploro, especificamente, a articulação entre performances de gênero e regimes de visibilidade presentes nas trajetórias de Valentim, Omar e Helano, respectivamente.

\section{Valentim: "tento não dar aquela pinta, que a gente tem, natural"}

Conheci Valentim (23 anos, "gay", "branco") numa situação curiosa: estávamos, dois amigos e eu, em um supermercado localizado na Avenida Visconde de Souza Franco (popularmente conhecida como Doca, na confluência entre os bairros de classe média Reduto e média alta Umarizal, na cidade de Belém, PA) - ponto de encontro de jovens homossexuais e heterossexuais, sobretudo pela variedade de bares, boates e estabelecimentos comerciais. Naquela ocasião, conversávamos sobre relacionamentos entre homens homossexuais, especificamente a respeito do fato de estar cada vez mais complicado arrumar um parceiro, e que sair para "baladas" não é a melhor maneira de estabelecer algum tipo de relacionamento.

Passados alguns minutos, Valentim se aproximou e sentou na mesa onde estávamos. Meus amigos começaram a trocar informação com ele, mas eu não dei tanta atenção. De repente, ele me olhou e disse: "Conheço seu trabalho, sei o que você pesquisa, sei quantos anos você tem". Achei aquilo estranho e retruquei de maneira impulsiva: "Ah! Encheção de saco uma hora dessa!". Na verdade, naquele momento eu não percebi que se tratava de uma cantada, não pensei que poderia, na visão dele, ser um parceiro em potencial, ou alguém que ele tivesse admiração pelo trabalho, apenas não gostei daquele tipo de abordagem.

Aquela situação de "assédio" e paquera me fez, inevitavelmente, refletir sobre a subjetividade do pesquisador em campo. Nas minhas incursões durante o mestrado, nas boates Lux e Malícia, minha preocupação era menos sobre o fato de eu ser gay e mais no que a relação entre ser gay e o meu dress code poderiam ser rentáveis à pesquisa. Comecei a perceber que vestimentas 
e comportamentos delimitados pela frequência a determinado espaço geravam diferentes olhares e investidas.

Como se tratavam de boates que agregavam públicos distintos, marcados principalmente por diferenças de classe e performance de gênero, quando eu ia na Malícia me produzia mais: usava roupa "da moda", utilizava menos maquiagem, mantinha discrição, geralmente gastava mais dinheiro com bebidas por conta do preço elevado, contudo, no momento em que meus movimentos de dança começavam a ficar "mais feminilizados", eu passava, automaticamente, de parceiro em potencial para sujeito não desejável, acrescenta-se a isso que o meu tipo físico não era atraente naquele espaço (sou magro e baixo).

Quando eu me deslocava para a Lux também prestava atenção na vestimenta, porém a diferença é que eu tinha menos preocupação com o uso de grifes, o que me possibilitava ter uma liberdade maior para compor um visual "mais transgressor" (menos careta). Enquanto na Malícia, eu ia de calça jeans, sapatênis, camisa pólo/ social, na Lux eu usava de maneira mais frequente bermudinha ou calça jeans skinny, maquiagem exagerada, camisas ou camisetas com decote maior. Com relação às investidas afetivo-sexuais, confesso que recebia mais cantadas na Lux, tanto dos "mais velhos" quanto dos "mais novos", e como eu não me preocupava em "fazer carão", eu percebia que naquele espaço as pessoas se sentiam mais livres para dançar, comprar bebida barata, mostrar o celular que não era de última geração, enfim, não havia uma preocupação exagerada sobre a imagem e com os comentários de terceiros.

Parte dessas minhas preocupações em refletir sobre subjetividade em campo têm como base um conjunto de etnografias brasileiras nas quais o "assédio" e a paquera, do interlocutor para o pesquisador, estiveram presentes (Meinerz, 2011; Lacombe, 2005 e 2010; Oliveira, 2006; Facchini, 2008; França, 2012; Braz, 2010). Em âmbito internacional, tal negociação (management) serve para ilustrar um não maniqueísmo moralizante entre se envolver ou não se envolver afetivo-sexualmente em campo (Wafer, 1996; Newton, 1996; Williams, 1996), marcando duras distinções entre professional lives e private lives (Wafer,
1996). A premissa que se coloca é que, de acordo com alguns antropólogos, a identidade sexual deve estar restrita à vida íntima. Será? Não cabe dizer que a partir de agora todos os antropólogos gays e lésbicas devem começar a se envolver afetivo-sexualmente com seus interlocutores, sob a justificativa de que tal relação sofisticaria insights, além de abrir diversas portas, mas é preciso trazer à baila esse debate. No que concerne aos meandros de como equilibrar possíveis dimensões eróticas no trabalho de campo, Esther Newton (1996) enfatiza que:

So by the "erotic dimension", I mean, first that my gay informants and I shared a very important background assumption that our social arrangements reflected that women are attracted to women and men to men. Second, the very fact that I have worked with other gays means that some of the people who were objects of my research were also potential sexual partners. Partly because of this, my key informants and sponsors have usually been more to me than an expedient way of getting information and something different than "just" friends. Information has always flowed to me in a medium of emotion, ranging from passionate - although never consummated - erotic attachment through profound affection to lively interest, that empowers me in my projects, and when it is reciprocated, helps motivate informants to put up with my questions and intrusions (Newton, 1996: 220-221).

Com o decorrer da pesquisa de campo e das minhas idas na boate Malícia, continuei encontrando Valentim, cumprimentávamo-nos e ele sorria e falava: "Encheção de saco uma hora dessa!". Eu, inevitavelmente, sorria ao lembrar da nossa primeira aproximação. Após alguns encontros na boate referida, aproximei-me dele e expliquei sobre o que me levava a frequentar, assiduamente, aquele espaço. Então, resolvi perguntar a ele se aceitaria ser entrevistado. Ele reagiu com entusiasmo e aceitou o convite.

Valentim mantinha uma performance corporal "mais masculinizada" e fazia questão de evidenciar que não se relacionava afetivo-sexualmente com homens homossexuais "afeminados". Ele era visto pelos demais 
"homossexuais" como "mona ocó" (mantinha discrição, não gostava de "dar pinta" e se sentia constrangido ao estar próximo de homens homossexuais "afeminados"). Uma situação de constrangimento, por exemplo, foi quando nos encontramos na Malícia e eu estava usando uma bermudinha. Quando Valentim me avistou, perguntou: "Porque você tá usando isso?". Ambos levamos na brincadeira, mas eu podia notar como ele ficou constrangido ${ }^{8}$.

O breve relato acima interpela indiretamente o processo de socialização pelo qual passou Valentim. Durante a infância e a adolescência ele morou em uma cidade no interior do Pará (São Miguel do Guamá), onde teve uma educação cristã, quando participou de um grupo em uma igreja católica. Sua iniciação sexual ocorreu com meninas, aos onze anos, uma espécie de ato despropositado, "uma sacanagem", conforme relatou. Com relação à homossexualidade, havia uma questão que envolvia "aceitação" e "medo". Ele se recusava a ser identificado como "homossexual", tampouco como "gay".

As convenções sexuais e de gênero nas cidades do interior do Pará parecem ter um peso muito forte no que concerne à ratificação de uma conduta heterossexual e à negação e o apagamento da homossexualidade: se "assumir" nesse contexto é ser chamado de "boiola",

7 "Ocó": homem no bajubá ou pajubá. Dentro desta economia gramatical, Ribeiro (2010: 1-2) percebeu em sua pesquisa sobre o coming out de jovens gays em Belém, que o bajubá, "além de fazer uma mediação entre a identificação subjetiva e a identificação coletiva, ajudava a entender um pouco das relações de poder existentes entre LGBT, pois as formas de apropriação e de classificação presentes neste léxico marginal são parte de uma 'cosmologia', de um conjunto de significados, de um conjunto de representações, e por que não dizer de explicações dos preconceitos e discriminações por parte de quem fala; do sujeito falante, pois mesmo que, inadvertidamente, se aproprie de nichos dessa linguagem acaba levando consigo os traços das relações de poder emanadas pelo constructo semântico". "Mona ocó" é semelhante ao termo "bicha-boy" presente em Oliveira (2006).

8 Durante minhas incursões a campo, de 2010 a 2012, sempre deixei claro a maneira como gostava de me vestir (com roupas justas, bermudinha, calça skinny, embora nem sempre compusesse tal vestual) e minha orientação sexual homossexual. Percebi que esses dois fatores me ajudaram a ganhar "confiança" dos interlocutores desta pesquisa, seja por meio da verbalização de questões que não eram colocadas no âmbito familiar de cada um deles ou, então, pelo modo irônico ou sincero que me abordavam. Sobre ser gay e fazer trabalho de campo, ver: Williams (1996).

9 O "armário" enquanto um dispositivo de regulação social é, para muitos homens homossexuais, "a característica fundamental da vida social, e há poucas pessoas gays, por mais corajosas e sinceras que sejam de hábito, por mais afortunadas pelo apoio de suas comunidades imediatas, em cujas vidas o armário não seja ainda uma presença formadora." (Sedgwick, 2007: 22). "fresco", "baitola", "viado", "bicha". Deste modo, o processo de "aceitação" da homossexualidade possui uma relação de complexidade que se aproxima da relação estudada por Veena Das (2011: 15), “entre a violência como momento originário e a violência que se infiltra nas relações correntes e se torna uma espécie de atmosfera que não pode ser expelida para 'fora"'.

Permeado por essa atmosfera, Valentim ainda conseguiu sustentar uma relação dupla com um homem e com uma mulher, quando tinha vinte anos. Seu primeiro contato com outro homem, ou melhor, a primeira conversa sobre homossexualidade aconteceu em um ambiente religioso: ele conheceu um rapaz que chamou sua atenção para as questões sobre homossexualidade, pois assuntos que tratassem desse tema não eram abordados no ambiente familiar.

Nesta narrativa e nas demais, é possível perceber que o processo de constituição de subjetividades homossexuais está coadunado com a criação de redes (de conhecidos ou de amigos) que extrapolam os limites da casa (Epstein, 1969), bem como apontam uma maior "aceitação" de suas homossexualidades para fora de casa, afinal a todo momento o nome da família está em jogo e sua reputação pode ser "manchada" dada a descoberta de se ter um filho "boiola", "fresco", "baitola", "viado", "bicha”, através da fofoca e do escândalo (da vizinhança), vistos como mantenedores da unidade moral e dos valores de grupos sociais (Gluckman, 1963; Fonseca, 2000) ${ }^{10}$.

É mister ressaltar a rigidez subjacente à construção de papéis sexuais e de gênero no Brasil: homens devem ser fortes, provedores, não sensíveis e terem relações sexuais com mulheres para fins de procriação. As mulheres, por sua vez, estão vinculadas à maternidade e sensibilidade, além de estarem propensas à passividade (Fry \& MacRae, 1991). Essa presunção é posta em cheque quando Butler (2013) problematiza o que ela chama de "matriz de inteligibilidade heterossexual" (coerência sistemática e linear entre sexo, orientação sexual e desejo).

Essa "matriz de inteligibilidade heterossexual" interfere diretamente no posicionamento dos entrevistados em espaços que não são apenas de sociabilidade

10 A questão da circulação como "facilitadora" para a publicização da homossexualidade, além de funcionar como um importante vetor de (re)criação de estratégias de apropriação do espaço urbano, também são aspectos tangenciados nas seguintes pesquisas: Puccinelli (2013), Facchini (2008), França (2012), Reis (2013; 2015c). 
homossexual. A publicização da identidade de gênero "gay" de Valentim se desacentua quando ele entra em um espaço de sociabilidade heterossexual: "Procuro ficar na minha, tento não dar aquela pinta, que a gente tem, natural". Nesse caso há um posicionamento de receio e de cuidado com a imagem, mas não só, no que se refere à busca por parceiros. Ele se considera tímido e acredita que espaços de sociabilidade heterossexual, por exemplo, não são lugares rentáveis para a busca por homens homossexuais. Sobre a imagem, ele comenta: " $E$ preciso ser bem visto, não manchar a reputação, se dar o respeito."

A "pinta" e o "respeito" são termos êmicos construídos em oposição e sob o signo de uma equivalência comportamental, ou seja, enquanto a "pinta" está atrelada ao gesto, à voz e ao corpo espalhafatoso, o "respeito" é a ação que mescla uma compleição corporal baseada em "cálculos" (Oliveira, 2013) estritamente pensados com vistas a não borrar imagéticas padronizadas.

Júlio Simões et al. (2010), em um estudo realizado em espaços de sociabilidade juvenis homossexuais e heterossexuais, na região do "centro velho" da cidade de São Paulo, observaram que:

[...] os tipos que parecem mais masculinos, mais discretos e menos espalhafatosos tendem a ser os mais desejados. Assim, é possível observar uma contenção dos rapazes de performance mais feminina quando se engajam efetivamente na paquera e no esforço de atrair alguém que lhes tenha despertado interesse ou lhes dirija a atenção (Simões et al., 2010: 53).

Este argumento corrobora com a ideia de que um relacionamento pode ser medido, de algum modo, pela frequência da interação, bem como pelo seu conteúdo. No limite, todo relacionamento, para além do caráter afetivo-sexual, envolve a ideia de troca, e o que ajuda a defini-lo, no caso dos pares, são os tipos de informações e opiniões que são trocadas (Epstein, 1969). Assim, quanto maior for a intensidade simétrica da relação entre pares, o fortalecimento de redes será mais consistente.

Voltei a indagar Valentim sobre a sua relação com a família de origem, a respeito da identidade/nomeação "gay", ele me respondeu a partir de situações que ocorreram durante sua adolescência. $\mathrm{Na}$ época, Valentim não tinha namorada e foi questionado por uma tia sobre os seus relacionamentos, ao passo que ele teve que "abaixar a cabeça" e se sentiu reprimido diante dos primos, que automaticamente relataram seus envolvimentos com garotas.

Em uma das conversas sobre sexualidade, Valentim e sua mãe (sob efeito alcoólico) debateram o fato dela ter comentado, indiretamente, sobre o possível relacionamento do filho com um rapaz. Ele não hesitou em dizer que seria "o que quisesse ser e que continuaria sendo a mesma pessoa". No dia seguinte, sem a presença do pai, apenas da irmã e da mãe, Valentim tentou continuar a conversa, mas a irmã e a mãe retrucaram dizendo que achavam "nojento duas pessoas do mesmo sexo". Seu maior medo é que a família "vire às costas" e comece a vê-lo como uma "pessoa inferior".

Perguntei a ele como se comporta em ambientes extrafamiliares, ele admitiu que não fala que é "gay". Ele comentou: "Pra falar a verdade as pessoas que eu tenho mais diálogo são pessoas bem entendidas, que tem mais ou menos um mundo. São pessoas que tem um conhecimento maior pra amizade, então, entendem mais sobre o que é ser homossexual, até por terem amizades homossexuais."

Caminhando para o fim desta seção, perguntei a ele qual o seu posicionamento com relação às questões que dizem respeito à homossexualidade e à "saída do armário", ele respondeu: "Eu acho que isso é uma escolha individual. Eu acho que cada um tem uma trajetória de vida e cada um tem uma forma de manifestar pensamentos, atitudes, ideias, da maneira que quer. Então, tipo, se uma pessoa é totalmente afeminada, eu creio que primeiro ela é aquilo porque ela quer; porque ela foi criada para ser daquele jeito; porque os hormônios dela propiciam que ela seja aquilo. Se uma pessoa é mais reservada, eu acho que é porque ela foi criada para ser daquele jeito; ela quer ser daquele jeito por conta da opressão social; e ela é porque ela gosta, até mesmo de se relacionar com pessoas que não sejam tão afeminadas".

Na pesquisa que Gustavo Saggese (2009) realizou sobre os modos de subjetivação de homens homossexuais através do coming out - processo não-sequencial e inacabado, o autor percebeu que, além de consistir em um esforço de "desaprendizagem", a "saída do armário" em contextos onde algum membro da família assimilou este posicionamento de forma positiva e não-preconceituosa e/ 
ou vexatória se fez presente um "discurso que enfatiza uma maior 'liberdade' de trânsito no ambiente familiar, bem como uma aproximação afetiva, que parecem contribuir para uma maior integração da homossexualidade na vida cotidiana e em espaços públicos mais formais" (idem: 39 ).

\section{Omar: "não precisa chegar na festa e ficar se beijando, ficar se agarrando e ficar mostrando as nossas afetividades"}

Conheci Omar (39 anos, "homossexual", "negro") em uma noite durante a minha ida na extinta boate Paparazzo (na época, localizada no bairro Reduto). Avistei-o escorado em uma pilastra nos fundos da boate. Omar, natural de Pernambuco, compunha uma estética atraente naquele espaço: o fato de ser mais velho, careca, "coroa enxuto", "negro" e másculo eram características que atraíam o público jovem presente. Eu olhava de longe os vários rapazes homossexuais que se aproximavam dele. Após um tempo observando aquelas investidas, resolvi me aproximar e conversar com ele.

Mantivemos diálogo em momentos oportunos, sem que eu desse algum indicativo de que se tratava de uma pesquisa. Porém, no momento em que eu revelei a ele minhas reais intenções percebi um certo afastamento ou fuga de uma situação que o atrapalhava na busca por parceiros, conforme ele alertou: "Uma boate não é lugar pra fazer pesquisa!". Embora eu não mantivesse um diálogo monopolizado com Omar, não me afastei dele sem antes trocarmos contatos (telefone e e-mail). Passados alguns dias, conversamos por telefone e eu consegui agendar uma entrevista com ele na Universidade Federal do Pará (UFPA).

Gostaria de abrir um parêntese, ainda que breve, a respeito dos meandros de uma etnografia desenvolvida por um antropólogo gay sobre "gays". Aquele meu primeiro contato com Omar me instigou a fazer a seguinte reflexão: não obstante eu ter revelado, na primeira oportunidade, que a minha investida se tratava de uma pesquisa e não de uma possibilidade fortuita de interação afetivo-sexual, por que Omar resolveu continuar o diálogo e decidiu me conceder a entrevista já que eu não tinha declarado minha orientação sexual?

James Wafer (1996) vislumbra questionamentos interessantes e bons para pensarmos:
What would this mean anthropology, specifically for researchers engaged in fieldwork and ethnographic writing? Is it possible to imagine a "gay ethnography"? Anthropologists who have a gay sensibility might think that a gay ethnography is one that sleeps with other ethnographies (the ultimate form of intertextuality). But let me try to characterize it in a more scholarly fashion. A gay ethnography would be one in which the identity of the ethnographer as a lesbian or as a gay man is an explicit and integral part of the text. At the time of writing, there have been very few ethnographies that would fit this definition. One of the reasons for this, I suspect, is that the writing of a gay ethnography entails greater risks than the simple matter of coming out of the closet because it threatens cultural norms in a more profound way (Wafer, 1996: 261-262).

Talvez não seja o caso de eu afirmar que desenvolvi uma "etnografia gay". A despeito de ficar explícito, neste texto, a minha orientação sexual, os diálogos iniciais que travei com meus interlocutores não tomaram como ponto de partida a publicização da minha orientação sexual; não considerei primordial tomar tais atitudes, apesar de compreender que verbalizar a orientação sexual do pesquisador, em campo, dependendo da situação poderia abrir portas e ser extremamente vantajoso (cf. Williams, 1996).

Durante a entrevista com Omar, ele lembrou do tempo em que tinha dezoito anos, período em que exercera a função de presidente de grêmio estudantil em um colégio na Bahia. Nesse período, ele recordou suas amizades com outros "gays". Segundo ele, as maneiras que usava para "reconhecer" que um menino era "gay" se davam por um processo de imputação. Ele comentou: " $E$ gente que faz!"; "É gente do meio!". Nessa mesma época, Omar contou que teve um relacionamento heterossexual, o que gerou uma filha, que na ocasião da entrevista tinha dezessete anos.

Segundo Omar, não havia nesse período uma configuração/conceituação do que para ele seria a conjunção "homem-homem", "mulher-mulher". A relação afetivo-sexual entre homens só veio acontecer quando ele completou dezenove anos: "E aí, com dezenove anos eu decidi passar o carnaval em Recife. Então, eu tive o primeiro contato com outro homem: o cara veio, deu 
em cima de mim, mas eu fiquei sem ação. Ele era mais velho. Eu só sei que, finalmente, aconteceu... como se fosse uma coisa natural, mas que deixaria de ser natural depois, quando eu comecei a refletir sobre o que havia acontecido, porque havia acontecido, todos os porquês da vida. Então, depois desse primeiro contato eu voltei pra Salvador, porque eu tava de férias. Quando eu voltei pra Salvador eu não podia mais me esbarrar ou olhar pra um rapaz, que eu já tinha um sentimento, uma atração, vontade de ficar, enfim... e isso foi aflorando logo após o primeiro contato".

Após esse primeiro contato sexual com outro homem, a percepção de Omar sobre o "universo gay" havia ficado "mais aguçada". Ele afirmou que seu maior dilema foi dispensar as meninas: o fato de "não saber lidar com o assédio das garotas, e ter que dispensálas". Após ter se "aceitado" enquanto "homossexual", ele não queria ter uma vida dupla, com "mentiras" e "ocultamentos" da realidade, não precisando mais dizer que era "heterossexual", pois durante algum tempo Omar viveu uma "dupla identidade". Ele relatou: "quando eu falava pras garotas que eu gostava de homens, elas se assustavam, era complicado. Era mais complicado lidar com as meninas que continuavam dando em cima de mim. Também tinha toda aquela questão de eu me relacionar ou dialogar com os rapazes gays da cidade, do bairro."

Quando perguntei a ele o que era ser "assumido", Omar respondeu: "Eu acho que ser assumido é viver a sua sexualidade sem medo, sem tabus, sem estigmas. É viver com liberdade, sem medo de ser feliz, mas, principalmente, entendendo o que é viver essa sexualidade e o que é ser assumido pra si”. Independente das demais coisas citadas por Omar e que compõem a construção da sexualidade, segundo ele: "É preciso se aceitar primeiro, as aceitações da família e da sociedade são consequências do meio, não são uma obrigação".

Compreendo, a priori, o que chamo de "ocultamento" da realidade como uma "estética dos sentidos" (Das, 2011), corroborada a um exercício forçoso de compleição corporal para a representação de moldura e encaixe dentro de uma lógica violenta e rígida.

Diante dos gestos performáticos que os homens homossexuais entrevistados exercem em suas trajetórias, tal "estética" molda rosto e corpo, circunscrevendo-os em tempos, espaços e contextos distintos, e promovendo a publicização de uma "homossexualidade masculinizada", por exemplo. Nesse sentido, a partir da representação de uma "nação masculina/masculinizante/masculinizada" (Das, 2011), ou de uma construção de identidade local máscula, o tornar-se sujeito homossexual pode ser entendido como uma experiência de sujeição.

Ao recordar sua criação familiar, Omar enfatizou que houve surpresas com relação ao seu processo de “aceitação". Ele percebeu que o pai, diferente da mãe, agiu de maneira "mais natural". Contou ainda que teve sérios problemas com a mãe, inclusive chegou a sair de casa por causa dela, voltando a morar com ela somente quando o pai a convenceu de que a homossexualidade de Omar não era uma doença e nem uma aberração. Quando o pai faleceu sua mãe iniciou um processo de aproximação, que se refletiu na seguinte cena: de uma mãe que procura ler e entender sobre a homossexualidade através de jornais e revistas, assistindo programas que abordem o tema na TV, fazendo com que mãe e filho possam dialogar mais sobre o referido assunto ${ }^{11}$.

Com relação aos amigos, todos com quem Omar se relaciona sabem da sua orientação sexual, contudo ele ressaltou que: "Deve sempre haver respeito nas relações, independente da orientação sexual das pessoas. Isso faz parte da prática, do comportamento, das limitações em sociedade. Você tem que entender o espaço do outro". Ele comentou que se sente uma pessoa "mais livre" para viver sua sexualidade, "não mascarando e tampouco forçando a exposição dela para todos". Tal liberdade evocada diz respeito ao fato dele morar sozinho, desde os vinte e três anos.

Segue uma importante fala de Omar como forma de ilustrar o parágrafo acima: "Hoje minha mãe não me questiona porque sabe que é um fato consumado e não tem jeito, mas a minha avó materna ainda fica batendo na tecla: 'Ah, meu filho, você ainda vai constituir uma família...' Pelo fato de eu ter tido uma filha, isso fica muito enraizado na cabeça delas. Porque, por exemplo, a sociedade ainda acha que o gay é aquele que não come mulher, que não faz filho, então a sociedade tem falta de informação. Em geral, o leigo acha que o gay é sempre aquele que quer ser mulher, vê o gay como uma travesti, vê o gay como um homem que se veste de mulher. A sociedade, na sua grande maioria, tirando os que não

11 Sobre casos como esse, ver: Saggese (2009). 
tem acesso à informação, acha que o gay é sempre o afeminado; por isso que nós temos uma massa enorme de homens em práticas homoeróticas, mas que costumam se passar como heterossexuais".

Omar compreende que hoje há certa dificuldade em perceber a orientação sexual de determinado indivíduo por conta do comportamento, por exemplo: "Quando você é um gay estereotipado, afeminado, afetado, então isso tá: água e vinho, melhor do que água e óleo que não se mistura; mas assim, quando você é um homossexual que tem um comportamento mais masculinizado, isso passa despercebido entre os amigos". Nesse sentido, ele faz questão de não publicizar a sua orientação sexual: "É o que eu falo sempre, não precisa chegar na festa e ficar se beijando, ficar se agarrando e ficar mostrando as nossas afetividades, mas também não é proibido, eu acho que não é necessário, mas também não é proibido". Esse limite simbólico de conduta, algo que pode e não pode ser construído em simultaneidade, é a afirmação e a reafirmação contínua de tensões e conflitos na constituição de identidades e performances de gênero.

Notei como o exercício de "sair (ou não) do armário", ou melhor, de visibilizar ou invisibilizar condutas homossexuais, em âmbitos intra e extrafamiliar, funciona como dispositivo de regulação social/sexual. A premissa estabelecida por Omar age enquanto um efeito de "desdiferenciação" marcado por temporalidades específicas (Meccia, 2011), além de sustentar uma lógica intransponível e não relacionável entre performances de gênero "afeminadas" e "mais masculinizadas", cuja metáfora da não mistura entre água e óleo parece fazer todo sentido.

Lembrei, por exemplo, que a distinção existente nas boates que pesquisei em Belém se materializava na produção de performances de gênero vinculadas a determinadas clientelas.

Podemos pensar que a circulação de travestis, Drag Queens, transexuais, praticantes de cross-dressing, no ambiente da Lux traria feminilidade para o local, tal como afirmou um entrevistado? Até que ponto isso pode ser levado em consideração? Bom, se pensarmos que na Lux há a liberação da entrada para aquelas pessoas que estiverem montadas (rapazes que se vestem com roupas do vestuário feminino), há a promoção de concursos de beleza negra, miss Pará gay etc. e onde é possível encontrar rapazes homossexuais mais jovens que estão passando por um "processo de aprendizado" de determinados códigos de sociabilidade e cada vez mais se "feminilizando", seja pelo simples prazer de usar roupa do vestuário feminino ou para facilitar a entrada, visto que são de classes sociais mais baixas e, isso ajudaria a se "encaixarem" nesse universo, tais hipóteses se confirmam na repulsa e recusa a esta "feminilidade periférica e espalhafatosa" que é (re)produzida pelos frequentadores da Lux em contraposição a uma masculinidade respeitável (re) produzida pelos frequentadores da Malícia (Reis, 2012b: 85).

A articulação entre espaços de sociabilidade homossexual e vivências homossexuais individuais recai novamente em duas questões importantes deste texto: "se dar o respeito" em oposição a "dar pinta". Nesse sentido, "se dar o respeito" é o oposto a "dar pinta" pela construção de que a respeitabilidade, para os homens homossexuais entrevistados, não é o laço que os une, afinal "nem todos são dignos de respeito", pois são diferenciáveis entre si.

A construção de subjetividades homossexuais agenciadas pelo fator espaço e tempo é uma problemática que deve ser encarada para uma melhor compreensão do debate sobre velhos e novos regimes de visibilidade homossexual ${ }^{12}$. Quando Ernesto Meccia (2011) argumenta que a "gaycidade" é uma maneira de compreendermos as transformações contemporâneas em torno da homossexualidade, não é somente porque se trata de uma questão geracional, mas que determinados contextos ajudaram a construir noções de sujeito associados a performances de gênero e estilos de vida específicos e idealizados.

Os tipos ideais ("incorporado", "sensato",

$12 \mathrm{Na}$ esteira dessas querelas, marcadas inevitavelmente por aspectos etários e geracionais articulados a espaços, lugares e ambientes on e off line, podemos perceber certa aproximação com a ideia de fluidez temporal presente na pesquisa de Guilherme Passamani (2015) sobre envelhecimento, memória e condutas "homossexuais" em duas cidades de pequeno e médio porte da região do Pantanal Sul-Mato-Grossense. O tempo, na perspectiva do autor, é um sinalizador utilizado para marcar o lugar da memória nas narrativas, além de indicar rupturas e permanências na maneira como são constituídas orientações sexuais e identidades de gênero no passado e no presente dos interlocutores e do pesquisador. Ademais, o tempo, para ele, também funciona para localizar espaços e gerações de homens com condutas "homossexuais" em momentos específicos, ao mesmo tempo em que movimenta-os dentro de determinadas dinâmicas de transformação social. 
"extrañado", "neutralista", “desafiliado", "replegado" e "contestatario") elaborados por Meccia, estabelecem aproximações edistanciamentos entreopassadoe opresente de homens homossexuais "mais velhos" que viveram o período ditatorial argentino, e portanto um "momento homossexual" marcado por perseguições, chegando nos dias atuais como espécies de "sobreviventes". Esse fator os fez questionar o próprio sentido de suas existências a partir de estatutos sociais que delimitam condutas para eles e para homossexuais "mais novos". A partir do que o autor chama de períodos "homossexual", "pré-gay" e "gay", foram produzidos agenciamentos caracterizados por processos de identificação que nivelam sensações de pertencimento por um crivo social entre o que deve, ou não, ser feito; bem semelhante, resguardando todas as discrepâncias contextuais, com o seguinte comentário de Omar: "eu acho que não é necessário, mas também não é proibido" 13 . O atual regime de visibilidade denominado por Meccia de "gaycidade" convive com diferenças entre períodos e agências, porque reúne sistemas de "desdiferenciação" (não compartilhados coletivamente) na promoção de uma sensação de igualdade entre homossexuais e heterossexuais, refletidas na construção de estilos de vida que se pretendem "semelhantes"14.

13 Este posicionamento reflete, em certa medida, a representação de comportamento do tipo ideal "sensato" (Meccia, 2011), qual seja: "Su punto de reflexión está de nuevo en los lugares abiertos para los gays y representa - por cierto - una paradoja. Si en un sentido advierte en los nuevos lugares una lógica de sociabilidad sectaria, desde otro punto de vista entiende que los nuevos lugares deben ser bienvenidos porque, en su conjunto, representan un espacio que "debe" existir para que los gays puedan manifestarse y expresarse en todas las dimensiones imaginables. Para el sensato, este es el gran legado social que han dejado las organizaciones que defienden los derechos de los no-heterosexuales. Notemos la extremada doble valencia que poseen dentro de esta re-configuración subjetiva los lugares gays, que pueden ser tanto "A" como "B", paritariamente. Los lugares A (el sensato piensa en las discos gays) son sectarios porque separan a los gays que tendrían que estar todos juntos, atentando contra el derecho de reunión y circulación; y los lugares B (el sensato piensa en las playas gays) representan el triunfo del derecho de reunión y circulación porque justamente - pueden estar todos los gays juntos sin ninguna clase de amenaza, mientras el resto de la sociedad también tiene sus playas. ¿Cuál es el problema?, piensa. ¿Acaso está mal que puedan juntarse los gays? ¿Acaso no está bien estar cerca de las personas con las que uno se siente más a gusto? ¿Quién podría prohibir eso? ¿Hasta ese punto podría inmiscuirse una ley, una decisión gubernamental? En realidad, allí estaría la verdadera discriminación, porque si esa ley llegara a existir sería una evidencia indiscutible de que los gays podrían ser gays puertas adentro, no debajo del sol” (Meccia, 2011: 62-63).

14 A esse respeito, ver: Saggese (2015).

\section{Helano: "[...] eu não fico me rasgando."}

Fui apresentado a Helano (25 anos, "homossexual", "moreno") em ocasiões festivas nas casas de determinados amigos em comum. Alguns encontros e conversas que tivemos na UFPA também me ajudaram nesse processo de aproximação. Quando comentei sobre a pesquisa que estava desenvolvendo ele aceitou com entusiasmo ser entrevistado. Eu percebi que ele sentia a necessidade de falar sobre questões que envolvessem sua sexualidade.

Durante a entrevista, ele contou que vivia uma "vida de reservas", pois seus pais até aquele momento não sabiam da sua orientação sexual. Segundo ele: "são poucos os amigos que sabem". Helano pareceu desconfortável com o fato de ter que falar sobre sua homossexualidade: "A minha trajetória foi muito independente. Eu não pude contar com ninguém, quer dizer, eu não quis contar com ninguém porque eu não tinha coragem de falar pra ninguém. Eu sei que pra muitas pessoas eu poderia ter contado, poderia ter sido diferente, mas não foi. Foi desse jeito e ponto. Então, aprendi as coisas sozinho. Dei a cara à tapa, e fui descobrindo muitas coisas sozinho, por minha própria conta e risco, né?! E, vez ou outra, conversando com um e outro, mas sempre dizendo: 'Ah, porque é um amigo, porque é um...' Sempre usando uma terceira pessoa, onde no fundo cada pergunta que eu fazia, que era referente a uma terceira pessoa, na verdade era pra mim, era eu que estava querendo saber".

A noção de "vida de reservas" elaborada por Helano conjuga um "cálculo" entre emoção e razão prática (Oliveira, 2013); se há um desencorajamento que o acompanha em determinadas situações, não há como não perceber que o substrato dessa "reserva" sustenta contingências marcadas por um fundamento que molda e fabrica pessoas e corpos. Tendo em vista que as descobertas solitárias de Helano fizeram sentido a partir do momento que ele aprendeu coisas fora de casa, ou seja, fora do âmbito da família de origem, o "cálculo" emocional e prático subjacente ao seu comportamento não está circunscrito única e exclusivamente a um possível ensinamento religioso e/ou familiar, posto que a criação de uma terceira pessoa (espécie de "alter ego") além de colocá-lo em segundo plano, conduz suas próprias regulações normativas em torno do que eu compreendo como normatizações auto-imputáveis e imagináveis criadas tanto de maneira individual quanto na presença de terceiros. De 
fato, em todas as trajetórias aqui perscrutadas, trata-se de uma questão bem mais complexa do que a simples dificuldade em "se aceitar" enquanto "homossexual".

Os primeiros indicativos de que Helano sentia atração por homens se deu nos momentos em que assistia filmes pornô heterossexual. Segundo ele, a parte que mais chamava atenção era quando o pênis estava em destaque. Ele lembrou de uma situação ocorrida em âmbito familiar, que o fez pensar "muito bem" antes de "revelar" algo sobre sua sexualidade, quando sua irmã se assumiu "homossexual". O tratamento do pai e da mãe foram extremamente hostil e ríspido. Helano, de forma recorrente, pensava e refletia sobre a questão da independência pessoal. Para que ele "saia do armário" era preciso, primeiro, ser independente financeira e pessoalmente: "Eu prefiro sentir que é o momento certo. Eu só quero, de fato, que oficialmente saia da minha boca, essa é minha grande preocupação".

Pergunto, então, se se preocupou com a criação de "rótulos" sobre determinadas pessoas. Ele asseverou que o que chamou de "rótulos" dizia respeito ao "gay afeminado, alegórico, que fala fino, que se traveste, que se rasga na rua". Helano continua: "O meu mundo profissional é um meio muito machista, então eu opto por manter a minha discrição, porque eu não quero que as pessoas me deem um emprego ou que me tirem determinado emprego por conta da minha sexualidade. Eu quero, sim, fazer por merecer estar nesse emprego ou fazer merecer sair deste emprego, mas não por conta da minha sexualidade, não por conta de eu acordar ou dormir pensando em homem, eu quero ser reconhecido pelo meu trabalho. Eu sou uma pessoa formada com vinte e cinco anos, a um mês de terminar um mestrado, são poucos. Eu sei que são poucos. Se for botar numa tabela, num nivel nacional, eu vou estar dentro de uma minoria que eu acho que não chega nem a um por cento do geral, ou seja, uma classe instruida, certo?".

A principal justificativa sobre a questão do "assumir", ou não, a homossexualidade no trabalho, está ligada a questão da reputação, da imagem, tal como manter uma posição de "respeito", ser olhado e "ser respeitado". Acredito que, para além dos processos classificatórios ou taxonômicos em torno de "sujeitos em certos contextos [...] ou na revelação das assimetrias de poder que se constroem a partir da complexa e sutil operação dessas clivagens, vêse na tessitura do cotidiano disputas acerca da construção do "nós' e do 'outro"' (Moutinho et al., 2010: 174).

No convívio com determinados amigos, publicizar a homossexualidade se dá de maneira mais flexível, com menos discrição, pois, de acordo com Helano: "Há maior confiança nesses grupos. É como eu te falo, eu não faço questão de ficar contando. Existem algumas pessoas, sim, que eu faço questão de contar porque são meus amigos. Várias outras pessoas se encaixam como colegas, conhecidos, ou pessoas que eu, simplesmente, um dia disse oi e tchau! Mas os meus amigos, de fato, que eu me importo, e que se importam comigo, e eu sei disso por já ter prova de convivência, eu sinto necessidade de contar pra eles, quebrar todo tipo de segredo. Nesse sentido, eu venho contando aos poucos, não são todos... ainda tem alguns que eu me importo e que eu gostaria de contar, que eu quero que saibam, pra que eu possa conviver à vontade, ficar à vontade... ainda faltam, mas isso não é uma coisa desesperada, que eu vou logo correr atrás e contar. Eu gosto que as coisas fluam naturalmente".

Essa rede de amigos que se formam durante o processo de socialização extramuros (da casa da família de origem) dão conta de um arsenal de possibilidades de agenciamento e negociações em torno de relações dialógicas que estão para além da reiteração de dicotomias, ou seja, fazer parte de tais redes reforça, cotidianamente, não somente a constituição do eu, daquilo que os faz individualmente expressarem suas sexualidades, assim como não se sentirem violentados pela sexualidade do outro.

Com relação aos colegas de trabalho, nem todos sabiam de sua homossexualidade, ele fez questão de dizer que tem amigos "afeminados", mas que não conseguiria andar num grupo de travestis, por exemplo, ressaltou que é uma questão de imagem e de afinidades. Insistiu em dizer que é apenas uma questão visual. Perguntei a ele se procurava diferenciar seu comportamento na presença de homens homossexuais com performance feminina, ele respondeu: "Naturalmente eu me destoo porque eu não ajo dessa maneira. Eu, naturalmente, não ajo. E não é porque eu to na rua. Mesmo quando eu to dentro de um ambiente gay, onde as pessoas se sentem livres e à vontade, eu não fico me rasgando, e tal. Realmente, quando eu estou com os meus amigos e a gente fica na brincadeira, ai é outra história. Então, queira ou não, eu acabo, não é me destacando, eu acabo me destoando do grupo, porque se eu to cercado de pessoas que agem com 
muita feminilidade, eu não ajo daquela maneira”.

Correspondente à performance feminina questionada por Helano, o que o deixa mais constrangido é o "julgamento" dos outros homens homossexuais, amigos, ou não: "Porque a partir do comportamento que as pessoas vão ter junto comigo, vem uma série de julgamentos por fora. O fato de eu me importar sobre como as pessoas estão se comportando do meu lado me reporta à questão do julgamento. Como eu te falei, eu não quero ser olhado, ser taxado, por conta da roupa que eu visto, ou das pessoas com quem eu ando. Eu não quero que alguém me olhe e diga: 'Olha aquela bichinha!' Eu não quero isso! Eu não busco isso! Porque o meu comportamento não é esse, e não é uma coisa forçada. As vezes, até quando eu tento brincar, frescar, ficar mais feminino, fica sem graça, porque fica na cara que eu não to sendo natural, eu não consigo fazer com naturalidade. O que me incomoda é isso, ser julgado sem ser conhecido".

Quando falei que entre "dar pinta" e "se dar o respeito" há uma distinção baseada por equivalências comportamentais, é porque compreendo que tais acionamentos êmicos não são preexistentes, não vem antes do sujeito, porque se tornam inteligíveis/materializáveis na conjunção ficcional e regulativa elaborada sobre o que se é e o que se quer ser. Desta feita, só existe "pinta" e "respeito" porque existe sujeito, e porque a partir da produção de sujeitos também são produzidas diferenças.

Como nos lembra Butler (2014), argumentando sobre a função da norma na regulação do gênero:

A norma governa inteligibilidades, permitindo que determinadas práticas e ações sejam reconhecidas como tais, impondo uma grelha de legibilidade sobre o social e definindo os parâmetros do que será e do que não será reconhecido como domínio do social. A questão acerca do que estará excluído da norma estabelece um paradoxo, pois se a norma confere inteligibilidade ao campo social e normatiza esse campo para nós, então estar fora da norma é continuar, em certo sentido, a ser definido em relação a ela. Não ser totalmente masculino ou não ser totalmente feminina é continuar sendo entendido exclusivamente em termos de uma relação a "totalmente masculino" e “totalmente feminina” (Butler, 2014: 253).

As piadinhas, fofocas, comentários jocosos fazem, de fato, parte da tessitura do cotidiano destes homens homossexuais, pois eles estão envoltos ou interagem com as brincadeiras, fofocas, cotidianamente, seja por meio da brincadeira perante o seguinte comentário: "Olha aquela bichinha!", ou em situações de enfrentamento quando o termo "bichinha" é utilizado para estigmatizá-los. Vale lembrar que existe uma linha tênue em torno da piada, da fofoca e do humor, como elementos que ora desagregam, ora agregam, justamente porque são fenômenos culturais mantenedores de certa moral (Gluckman, 1963).

\section{Dos regimes de visibilidade: entre um passado não muito distante e o presente}

Nos últimos anos, com o advento das novas tecnologias, refiro-me mais especificamente aos aplicativos de "pegação" entre homens homossexuais"15 (Miskolci, 2014a e 2015; Braga, 2015), dos aumentos de grupos em torno de uma militância LGBT organizada e focalizada (Facchini, 2005 e 2009) e do acelerado crescimento de estabelecimentos comerciais cujas propostas servem para criar "mercados” e consumos específicos (França, 2012), as relações (não apenas de cunho afetivo-sexual), por exemplo, entre homens homossexuais têm exacerbado condutas distintas fortemente voltadas para uma proposição política de afirmação identitária de um lado, e para uma prescritiva discrição a favor de uma busca por "respeito", indiferenciação e certa credibilidade de outro.

Se a partir da década de 1960 a noção de "gueto homossexual", no Brasil, esteve ancorada não exatamente em pesquisas que se concentravam em estabelecimentos comerciais, mas também na constituição de redes de amizade homossexual (MacRae, 1983; Barbosa da Silva, 2005 [1958]; Guimarães, 2004 [1977]); é no processo de mudanças sociais que se inicia na década de 1980 e tem o seu ápice nos anos 2000 que uma maior expressão de "mercado" segmentado vem à tona (cf. Facchini, França \& Braz, 2014) ${ }^{16}$.

No que se refere a essa segmentação de "mercado" contemporânea, uma espécie de consumo libidinal, através

15 Grindr, Scruff e Hornet são alguns exemplos.

16 Cabe destacar que essa maior expressão de "mercado" segmentado inevitavelmente mostra direcionamentos para uma compreensão da cidade, basta ter em mente que se há uma expansão dos circuitos de lazer e sociabilidade homossexual em várias cidades brasileiras, a própria noção de segmentação indica o quê e quem deve ser atingido/ privilegiado, ou seja, são aspectos evidenciados em marcações de espaço-tempo e, sobretudo, de classe social. A esse respeito, ver: Simões \& França (2005), Puccinelli (2013). 
dos aplicativos de "pegação" para homens homossexuais, não somente produz sujeitos desejáveis, como também sentencia padrões corporais e identitários. Enquanto as sentenças "discreto e fora do meio" (Miskolci, 2015) e "não sou e nem quero afeminados" (Braga, 2015) têm atuado com fervor nesses aplicativos, tal demanda por discrição e sigilo são os pontos atacados pelos que confrontam esse padrão, chamado por muitos de "gay heteronormativo".

É curioso perceber que, se a partir dos anos 80 a percepção era de que barreiras de gênero vinham caindo uma a uma, em velocidade nunca dantes vista, certas representações nos circuitos homoeróticos masculinos contemporâneos reivindicavam sinais clássicos da masculinidade e, não raro, mobilizavam categorias que beiram à misoginia... nos ambientes virtuais de exercício do homoerotismo, em que a linguagem escrita ocupa um papel de destaque nas representações, o discurso "afeminofóbico" toma uma forma mais explícita; cópia e caricatura são mais ainda uma só coisa, a imagem do macho refletido se distorce a um ponto que parece exagerado aos olhos de muitos "machos heterossexuais” (Braga, 2015: 230).

Há, sobretudo, um encapsulamento por distinções de classe e de cor, pois grande parte desses "gays heteronormativos" são de classe média/média alta e brancos; não por acaso os gays que não se enquadram nesse perfil (re)criam estratégias de visibilidade pela resignificação do termo "bicha", tomando para si um compromisso político-corporal de assumir e publicizar suas identidades homossexuais sem o medo de conviverem com toda sorte de estigmas, preconceitos e discriminações.

Querelas e resignificações como essas estão presentes na própria constituição do Movimento LGBT brasileiro há mais de 30 anos. Fry \& MacRae (1991) enfatizam que

A peculiaridade dos primeiros grupos do movimento homossexual é que resolveu rejeitar tanto "entendido" como gay, preferindo ficar com o velho termo "bicha". Propondo uma nova "bicha", militante e consciente, a idéia era de conseguir esvaziar, tanto a palavra quanto o conceito que representava de suas conotações negativas. Se autodeterminar de "bicha" veio a ser uma maneira de "assumir" uma homossexualidade considerada mais "consciente" do que a dos gays e "entendidos" e obrigar a opinião pública a reconsiderar suas atitudes em geral (Fry \& MacRae, 1991: 24-25).

Enquanto os termos "gay" e "entendido" são construções classistas e higienizantes (Fry, 1982), a ambiguidade que envolve o termo "bicha" (Fry \& MacRae, 1991) sustenta que o esvaziamento de seu conteúdo negativo "autoriza" um certo grau de intimidade entre determinadas pessoas (Oliveira, 2006). De um lado "bichas" procurando borrar padrões, de outro "gays" e "entendidos" estanques em suas zonas de conforto. Abismo.

Se o panorama atual da homossexualidade nos brinda com novas possibilidades de interação a partir, por exemplo, dos aplicativos de "pegação", além da noção de "desdiferenciação" que parece aproximar diferenças entre homossexuais e heterossexuais por uma sensação de igualdade (Meccia, 2011); ainda assim, a velha noção de "gueto homossexual" tem voltado à cena nos últimos anos por conta, principalmente, de uma maior publicização de identidades por jovens homossexuais (em eventos como as Paradas do Orgulho LGBT, os "beijaços", a Marcha das Vadias, os Encontros de "Afeminados"). Explico. Enquanto cresce o número de "bichas assumidas", cresce também uma parcela de "gays heteronormativos" e homofóbicos (ou como alguns chamam: "afeminofóbicos") que têm olhado com desconfiança para gays efeminados, rechaçando-os por meio de violência física ou verbal. Os próprios aplicativos de "pegação" mostram que as barreiras entre ativo/passivo, "bicha"/“bofe", "discreto"/“rasgado", ainda estão longe de serem quebradas ${ }^{17}$.

17 Não posso deixar de notar que tais dicotomias, associadas de certo modo a um corpo saudável, fazem parte de uma conjuntura bem maior, qual seja: a da epidemia HIV/aids. Conforme destaca Miskolci (2014a: 71): "Demorei a perceber que a ênfase no corpo malhado, como sinônimo de "fora do meio", exigia recuperar representações correntes, entre o início da epidemia da aids até a comprovação da eficácia do coquetel antirretroviral no final da década de 1990, sobre os gays "do meio", ou seja, sobre homens sabidamente homossexuais. Alguns de meus colaboradores relatam lembrar da capa chocante da revista Veja com a face macilenta de Cazuza e uma manchete descrevendo-o como um doente de aids que agonizava em praça pública. Discursos e imagens associavam gays a comportamento sexualmente promíscuo, risco de contaminação pelo vírus hiv, o que os levaria a se tornarem - em termo corrente da época, "aidéticos" - compreendidos como homens moralmente condenáveis, cuja transgressão seria lida em seus corpos e em suas faces adoecidas". Sem dúvida, a distinção entre classe social e geração é fundamental para compreendermos a maneira como determinados homens homossexuais se posicionam e são afetados pelo contexto atual em torno do HIV e da aids. Zamboni (2014) aborda esse debate de modo pontual e instigante. 
É preciso minar nossas normas e previsibilidades terminológicas. Construir um sujeito político e social que consiga romper (não exatamente implodir) com uma precariedade arquetípica se torna efetivamente tão complexo quanto necessário. Vozes e performances dissonantes nesse debate são fundamentais, pois o gênero, enquanto um substrato complexo, deve ser desconstruído tal como numa assembleia, onde sejam permitidas "múltiplas convergências e divergências, sem obediência a um telos normativo e definidor" (Butler, 2013: 37). Portanto, enquanto regimes de visibilidade homossexual forem constituídos pela lógica chiaro-schuro (Miskolci, 2014a) continuará havendo medo, sofrimento, "armário", e tantos outros aprisionamentos.

$\mathrm{Na}$ recuperação das trajetórias de Valentim, Omar e Helano, utilizei-me de suas narrativas por meio da maneira como eles constroem regimes de visibilidade, levando em conta as vicissitudes coexistentes no processo de "saída (ou não) do armário", ou seja, os diversos "cálculos" (Oliveira, 2013) que estes indivíduos realizam para assumir ou não uma identidade "gay"/"homossexual" em determinados contextos.

A questão da descoberta da sexualidade foi meu ponto de partida. Procurei relacionar esse aspecto com questões de "aceitação" e/ou "saída do armário". Num primeiro momento, a família de origem aparece como atuante (seja para "aprovar" ou "reprovar") no que se refere à relação entre filhos e parceiros homossexuais, porém, na maioria dos casos, praticamente inexistem diálogos sobre sexualidade, pois nãoháaparatode sustentação: tais famílias possuem posturas "conservadoras" e "preconceituosas", não "aceitando" um filho homossexual, ou não o concebendo como sujeito em potencial para estabelecer relações de namoro e casamento, e tampouco um padrão de família nuclear heterossexual (homem, mulher e filhos - meninos e meninas -, todos heterossexuais).

Tanto no primeiro envolvimento sexual com homens quanto com mulheres, o aprendizado da sexualidade se deu de forma individualizada, através de um misto de vários componentes: experimentação, curiosidade, medo, vontade, desejo. Para os entrevistados, um fator que facilitou uma relação de abertura com a família, no que concerne à abordagem de assuntos sobre sexualidade, foi a independência financeira: "se sustentar", "não depender dos pais", "morar sozinho", foram recursos que abriram possibilidades de maior diálogo a respeito de suas orientações sexuais. Ainda assim, independente dos exercícios de "saída (ou não) do armário", é perceptível como está impregnado nos discursos, uma atmosfera de convenções sexuais e de gênero, acionadas a todo instante para explicação de padrões de masculinidade e feminilidade.

Nas relações com os amigos em espaços públicos, os entrevistados expuseram os limites comportamentais que devem haver: "ser discreto" e "se dar o respeito", "não dar pinta", "saber se comportar nos determinados ambientes", foram os mais reiterados. Não sei, ao certo, se "sair (ou não) do armário" facilita ou dificulta o convívio social (de fato, não é a compulsoriedade da publicização da identidade "homossexual" que está em jogo); alguns mostram, enfaticamente, que sim, porém mesmo aqueles que já "se assumiram" continuam impondo limites corporais, justificando que performances de gênero "afeminadas" seriam um chamariz para atitudes homofóbicas.

Podemos nos perguntar se a oposição existente entre "não dar pinta" e "se dar o respeito" anula uma possível relação de conjunção destes dois termos em um só corpo, tanto "afeminado" quanto "mais masculinizado"? Minha resposta utópica é não. Utópica porque na prática isso não acontece. Isto é, no cotidiano e nas descobertas dos meus interlocutores a distinção entre "afeminação" e "masculinização" continua sustentando normas autoimputáveis e imagináveis: aquilo que se elabora sobre si e o que a sociedade pensa a respeito de parâmetros "certos" e "errados". Como afirma Butler (2014: 253): "Gênero é o aparato pelo qual a produção e a normalização do masculino e do feminino se manifestam junto com as formas intersticiais, hormonais, cromossômicas, físicas e performativas que o gênero assume".

As vicissitudes que os interlocutores encontraram em um processo de construção identitária e de performance de gênero sinuoso e as minhas subjetividades enquanto pesquisador gay e efeminado, fizeram-me compreender que o cerne da questão não está na compulsória revelação da orientação sexual (embora eu esteja certo de que um posicionamento identitário faça total sentido na construção de políticas públicas); levando em conta que experiências individuais e coletivas são mapas históricos marcados por espaços e temporalidades distintas não 
cabe imputar posicionamentos, mas é imprescindível que nossos posicionamentos diários, em casas, apartamentos, escolas, universidades, ruas etc., não solapem pessoas, corpos, performances, mas se valham do confronto, da problematização, do ato de refutar padrões/normas/ regulações.

\section{Referências bibliográficas}

ADICHIE, Chimamanda Ngozi. (2014). Sejamos todos feministas. São Paulo: Companhia das Letras.

BARBOSA DA SILVA, José Fábio. (2005 [1958]). "Homossexualismo em São Paulo: estudo de um grupo minoritário”. In: GREEN, James \& TRINDADE, Ronaldo (orgs.). Homossexualismo em São Paulo e outros escritos. São Paulo: Editora Unesp. p. 41-212.

BRAGA, Gibran Teixeira. (2015). "“Não estou cobrando o que eu não posso dar": masculinidade simétrica no homoerotismo virtual". Sexualidad, Salud y Sociedad, n. 21: p. $225-261$.

BRAZ, Camilo. (2010). À meia-luz: uma etnografia imprópria em clubes de sexo masculinos. Tese (Doutorado em Ciências Sociais) - Programa de Pós-Graduação em Ciências Sociais, Instituto de Filosofia e Ciências Humanas da Unicamp, Campinas, SP.

BUTLER, Judith. (2014). "Regulações de Gênero". Cadernos Pagu, n. 42: p. 249-274.

(2013). Problemas de gênero: feminismo e subversão da identidade. Rio de Janeiro: Civilização Brasileira.

DAS, Veena. (2011). "O ato de testemunhar: violência, gênero e subjetividade". Cadernos Pagu, n. 37: p. 9-41.

EPSTEIN, Arnold Leonard. (1969). "Gossip, norms and social network". In: MITCHELL, J. C. (ed.), Social Networs in Urban Situations: Analyses of Personal Relationships in Central African Towns. Manchester: Manchester University Press. p. 117-127.
FACCHINI, Regina. (2009). "Entre compassos e descompassos: um olhar para o "campo" e para a "arena" do movimento LGBT brasileiro”. Bagoas, n. 4: p. 131158.

(2008). Entre umas e outras: mulheres, (homo)sexualidades e diferenças na cidade de São Paulo. Tese (Doutorado em Ciências Sociais) - Programa de Pós-Graduação em Ciências Sociais, Instituto de Filosofia e Ciências Humanas da Unicamp, Campinas, SP.

(2005). Sopa de letrinhas? Movimento e produção de identidades coletivas nos anos 90. Rio de Janeiro: Garamond.

FACCHINI, Regina; FRANÇA, Isadora Lins; BRAZ, Camilo. (2014). "Estudos sobre sexualidade, sociabilidade e mercado: olhares antropológicos contemporâneos". Cadernos Pagu, n. 42: p. 99-140.

FASSIN, Didier. (2008). "Beyond good and evil? Questioning the anthropological discomfort with morals". Anthropological theory, n. 4: p. 225-246.

FONSECA, Cláudia. (2000). Família, Fofoca e Honra: Etnografia de relações de gênero e violência em grupos populares. Porto Alegre: Editora da UFRGS.

FOUCAULT, Michel. (2007 [1979]). Microfísica do poder. Rio de Janeiro: Edições Graal.

FRANÇA, Isadora Lins. (2012). Consumindo lugares, consumindo nos lugares: homossexualidade, consumo e subjetividades na cidade de São Paulo. Rio de Janeiro: EdUERJ.

FRY, Peter. (1982). "Da hierarquia à igualdade: a construção histórica da homossexualidade no Brasil. In: . Para inglês ver: identidade e política na cultura brasileira. Rio de Janeiro: Zahar. p. 87-115.

FRY, Peter; MACRAE, Edward. (1991). O que é homossexualidade. São Paulo: Brasiliense. 
GLUCKMAN, Max. (1963). "Gossip and scandal”. Current Anthropology, n. 3: p. 307-316.

GUIMARÃES, Carmem Dora. (2004 [1977]). O homossexual visto por entendidos. Rio de Janeiro: Garamond.

LACOMBE, Andrea. (2010). Ler [se] nas entrelinhas. Sociabilidades e subjetividades entendidas, lésbicas $e$ afins. Tese (Doutorado em Antropologia Social) Programa de Pós-Graduação em Antropologia Social, Museu Nacional da UFRJ, Rio de Janeiro.

. (2005). "Pra homem já tô eu": masculinidades e socialização lésbica em um bar no centro do Rio de Janeiro. Dissertação (Mestrado em Antropologia Social) - Programa de Pós-Graduação em Antropologia Social, Museu Nacional da UFRJ, Rio de Janeiro.

LUTZ, Catherine; WHITE, Geoffrey. (1986). "The Anthropology of Emotions". Annual Review of Anthropology, n. 15: p. 405-436.

MACRAE, Edward. (1983). "Em defesa do gueto". Novo Estudos CEBRAP, v. 2, n. 1: p. 53-60.

MAHMOOD, Saba. (2006). "Teoria feminista, agência e sujeito liberatório: algumas reflexões sobre o revivalismo islâmico no Egipto". Etnográfica, v. 10, n. 1: p. 121-158.

McCLINTOCK, Anne. (2003). "Couro imperial: raça, travestismo e o culto da domesticidade". Cadernos Pagu, n. 20: p.7-85.

MECCIA, Ernesto. (2011). Los últimos homosexuales: sociología de la homosexualidad y la gaycidad. Buenos Aires: Gran Aldea Editores.

MEINERZ, Nádia Elisa. (2011). Entre mulheres: etnografia sobre relações homoeróticas femininas em segmentos médios urbanos na cidade de Porto Alegre. Rio de Janeiro: EdUERJ.
MISKOLCI, Richard. (2015). "Discreto e fora do meio - Notas sobre a visibilidade sexual contemporânea". Cadernos Pagu, n. 44: p. 61-90.

. (2014a). "Negociando visibilidades: segredo e desejo em relações homoeróticas masculinas criadas por mídias digitais”. Bagoas, n. 11: p. 51-78.

MOUTINHO, Laura et al. (2010). "Retóricas ambivalentes: ressentimentos e negociações em contextos de sociabilidade juvenil na Cidade do Cabo (África do Sul)". Cadernos Pagu, n. 35: p. 139-176.

NEWTON, Esther. (1996). "My Best Informant's Dress: The Erotic Equation in Fieldwork". In: LEWIN, E. \& LEAP, W. L. (eds.). Out in the field: reflections of lesbian and gay anthropologists. Chicago: University of Illinois Press. p. 212-235.

OLIVEIRA, Leandro de. (2013). Os sentidos da aceitação: Família e orientação sexual no Brasil contemporâneo. Tese (Doutorado em Antropologia Social) - Programa de Pós-Graduação em Antropologia Social, Museu Nacional da UFRJ, Rio de Janeiro.

(2006). Gestos que pesam:

performance de gênero e práticas homossexuais em contexto de camadas populares. Dissertação (Mestrado em Saúde Coletiva) - Programa de Pós-Graduação em Saúde Coletiva, Instituto de Medicina Social da UERJ, Rio de Janeiro.

PASSAMANI, Guilherme. (2015). Batalha de Confete no "Mar de Xarayés": condutas homossexuais, envelhecimento e regimes de visibilidade. Tese (Doutorado em Ciências Sociais) - Programa de Pós-Graduação em Ciências Sociais, Instituto de Filosofia e Ciências Humanas da Unicamp, Campinas, SP.

PUCCINELLI, Bruno. (2013). Se essa rua fosse minha: sexualidade e apropriação do espaço na "rua gay" de São Paulo. Dissertação (Mestrado em Ciências Sociais) Programa de Pós-Graduação em Ciências Sociais, Escola de Filosofia, Letras e Ciências da UNIFESP, Guarulhos, SP. 
REIS, Ramon. (2015c). “"'A cidade não se relaciona com a periferia": (des)centralidades e circulações de jovens homossexuais em bairros "periféricos" de São Paulo e Belém". In: Anais Eletrônicos do $39^{\circ}$ Encontro Anual da ANPOCS. Caxambu, Minas Gerais. p. 1-40.

(2013). "Do interior para a capital: algumas histórias sobre a iniciação sexual de jovens universitários em Belém”. In: CONRADO, Monica (org.). Juventudes em trânsito: a iniciação sexual em debate. Belém: Paka-Tatu. p. 115-154.

(2012a). Encontros e desencontros: uma etnografia das relações entre homens homossexuais em espaços de sociabilidade homossexual de Belém, Pará. Dissertação (Mestrado em Ciências Sociais) - Programa de Pós-Graduação em Sociologia e Antropologia, Instituto de Filosofia e Ciências Humanas da UFPA, Belém, PA.

(2012b). "“"Eu tenho medo de ficar afeminado": performances e convenções corporais de gênero em espaços de sociabilidade homossexual. Rev. NUFEN, v. 4, n. 1: p. 73-87.

RIBEIRO, Milton. (2010). “De bajubá em bajubá, onde será que vai dar? Apropriações, classificações e relações de poder em Belém-PA". In: Anais Eletrônicos do II Encontro da Sociedade Brasileira de Sociologia da Região Norte. Belém, Pará. p. 1-15.

SAGGESE, Gustavo. (2015). Entre perdas e ganhos: homossexualidade masculina, geração e transformação social na cidade de São Paulo. Tese (Doutorado em Antropologia Social) - Programa de Pós-Graduação em Antropologia Social, Faculdade de Filosofia, Letras e Ciências Humanas da USP, São Paulo.

(2009). Quando o armário é aberto: visibilidade e estratégias de manipulação no coming out de homens homossexuais. Dissertação (Mestrado em Saúde Coletiva) - Programa de Pós-Graduação em Saúde Coletiva, Instituto de Medicina Social da UERJ, Rio de Janeiro.
SEDGWICK, Eve Kosofsky. (2007). “A epistemologia do armário". Cadernos Pagu, n. 28: p. 19-54.

SIMÕES, Júlio Assis. et al. (2010). "Jeitos de corpo: cor/ raça, gênero, sexualidade e sociabilidade juvenil no centro de São Paulo". Cadernos Pagu, n. 35: p. 37-78.

SIMÕES, Júlio Assis; FRANÇA, Isadora Lins. (2005). “Do "gueto" ao mercado". In: GREEN, James \& TRINDADE, Ronaldo (orgs.). Homossexualismo em São Paulo e outros escritos. São Paulo: Editora UNESP. p. 309-336.

WAFER, James. (1996). "Out of the Closet and into Print: Sexual Identity in the Textual Field". In: LEWIN, E. \& LEAP, W. L. (eds.). Out in the field: reflections of lesbian and gay anthropologists. Chicago: University of Illinois Press. p. 261-273.

WILLIAMS, Walter. (1996). "Being Gay and Doing Fieldwork". In: LEWIN, E. \& LEAP, W. L. (eds.). Out in the field: reflections of lesbian and gay anthropologists. Chicago: University of Illinois Press. p. 70-85.

ZAMBONI, Marcio. (2014). Herança, Distinção e Desejo: homossexualidades em camadas altas na cidade de São Paulo. Dissertação (Mestrado em Antropologia Social) - Programa de Pós-Graduação em Antropologia Social, Faculdade de Filosofia, Letras e Ciências Humanas da USP, São Paulo.

Recebido em: 26/03/2017.

Aceito: 12/04/2017. 